\title{
Zuttiyeh Face: A View From the East
}

\author{
SONGY SOHN AND MILFORD H. WOLPOFF \\ Paleoanthropology Laboratory, Department of Anthropology, University of \\ Michigan, Ann Arbor, Michigan 48109
}

KEY WORDS Zuttiyeh, Paleoanthropology, Asia, Neandertal, Levant, Zhoukoudian

\begin{abstract}
We analyze the phylogenetic position of the frontofacial fragment from Zuttiyeh, Israel. This specimen is dated to the Middle Pleistocene (the latest estimate is between 250 and $350 \mathrm{kyr}$ ) and is associated with the Acheulo-Yabrudian, which makes it the oldest cranium from the region. It has been previously regarded as a Neandertal, and early "anatomically modern Homo sapiens," and a generalized specimen ancestral to both. These different phylogenetic interpretations of its features have a historic basis but in our view also result from a confusion of grade and intraspecies clade as valid sources of variation. We show here that generally the differences that distinguish Zuttiyeh from Neandertals are similarities it shares with the Zhoukoudian remains. These similarities involve a unique combination of features, and suggest the possibility of an ancestral relationship. It is less likely that Middle Pleistocene remains from Europe or sub-Saharan Africa are uniquely or significantly ancestral to Zuttiyeh. An accurate understanding of the relationship between populations of eastern and western Asia is important for resolving the more general questions surrounding the position of the Upper Pleistocene Levant populations in human evolution, including (1) whether there are significantly different contemporary Mousterian populations in the Upper Pleistocene, (2) whether Neandertals are clearly intrusive in the region, and (3) whether there is an early appearance of (what many workers call) "anatomically modern Homo sapiens." The hypothesis of a recent unique African ancestry for all modern humans is disproved by our study, which shows Asia as a significant source area for at least some living populations. (C) 1993 Wiley-Liss, Inc.
\end{abstract}

The critical geographic position and early date of the Zuttiyeh frontofacial fragment combine to make it pivotal in clarifying a number of problems surrounding the evolution of Homo in Asia. In this paper we present the context and associations of the 1925 discovery, discuss the historic basis for the differing interpretations of its phylogeny (including why it was never systematically compared with the Zhoukoudian remains), and establish the best case for its ancestry and relationships by comparing it with the Zhoukoudian sample as well as with Middle Pleistocene humans from Europe and subSaharan Africa. It is our intent to examine the issues surrounding local ancestry and evolution in the Levant, because their solutions are central to the hypotheses about modern human origins. We will examine the question of different Late Pleistocene lineages in the Levant, and the confusion of grade and intraspecies clade in interpreting these hominids-especially over the problem of whether "non-Neandertal" necessarily means "modern." Our use of the intraspecies clade concept is unconventional, resting on Huxley's (1958) older definition of clades as groups sharing common genetic descent. Because we use clade to describe a regional

Received August 27, 1990; accepted November 17, 1992. 
aspect of intraspecies variation, monophyly is not implied, and indeed cannot apply.

\section{GEOARCHAEOLOGICAL CONTEXT}

The Wadi el Amud enters the Sea of Galilee on its northwestern bank. A number of rich archaeological sites from the Late Pleistocene, such as Amud, are found along the gorge. Where it cuts through a low range of limestone hills, just 200 meters upstream from the Mugharet el Emireh, F. TurvillePetre discovered the Mugharet el Zuttiyeh (the Cave of the Robbers) in the spring of 1925. Subsequent excavation at this site during the month of June yielded a large human craniofacial fragment which became known as the Galilee, or Zuttiyeh, skull.

The archaeological sequence of the Middle to earlier Late Pleistocene in the Levant consists of three major complexes-the Upper or Late Acheulean, the Mugharan Tradition (Jelinek, 1981), and the Mousterian (reviewed by Bar-Yosef, 1989). The Mugharan Tradition, or the Acheulo-Yabrudian, is geographically limited in its range to the central and northern Levant. It can be further subdivided into three facies: (1) a facies with a high percentages of bifaces and flake scrapers (the Acheulean facies); (2) a facies in which scrapers are abundant and bifaces rare (Yabrudian); and (3) a facies rich in blades, end-scrapers, and burins (Amudian or "Pre-Aurignacian"). The Mugharan tradition is followed by the Mousterian tradition, which is characterized by the Levallois technique.

Zuttiyeh was uncovered at the base of the cave's archaeological sequence, in a shallow pit dug into the sterile sandy deposit which filled the lower part of the cave (TurvillePetre, 1927). Later, Garrod (1962) noted that the human specimen was under a layer which contained an Acheulo-Yabrudian (Mugharan) assemblage, similar to the industry of Tabun E (Bar-Yosef, 1988). This was later confirmed by the excavation of the remaining brecciated deposits (Gisis and Bar-Yosef, 1974). The association of Zuttiyeh with the Mugharan Tradition shows it to be archaeologically older than any of the Mousterian associated Levant specimens.

Schwarcz et al. (1980) provided Th/U dates for various stalagmitic layers, above and below the Acheulo-Yabrudian in the Zuttiyeh cave. These were $95 \pm 10$ and $97 \pm 13 \mathrm{kyr}$ (from the pre-Mousterian above), $148 \pm 6$ from the Acheulo-Yabrudian, and $164 \pm 21 \mathrm{kyr}$ (from the underlying travertine). Following this, Copeland and Hours (1983) proposed another date for the Acheulo-Yabrudian at Zuttiyeh of 140-150 kyr. Based on these publications, and his analysis of the Levant archaeological sequence, Bar-Yosef $(1988,1989)$ conservatively bracketed the date of the Zuttiyeh face to between 110 and $150 \mathrm{kyr}$ by uranium series, the most common age estimate to be widely cited. However, more recently he has gathered support for an even earlier date (Bar-Yosef, 1992). TL dates from Yabrud and ESR dates from Tabun D suggest a termination for the Acheulo-Yabrudian in excess of $200 \mathrm{kyr}$, and this is supported at least in part by the ESR dates for the AcheuloYabrudian from Tabun Ea-Ed: from $151 \pm$ 21 to $182 \pm 31 \mathrm{kyr}$ (early uptake) and $168 \pm 15$ to $213 \pm 46 \mathrm{kyr}$ (linear uptake). The correlation of Tabun E, F, and G with Isotope Stages 11-13 extends the base of the Acheulo-Yabrudian into the $400-500 \mathrm{kyr}$ age range. Bar-Yosef concludes that the Zuttiyeh specimen is most likely bracketed between 250 and $350 \mathrm{kyr}$. It is the earliest Levantine cranial fragment.

\section{ZUTTIYEH AS A LEVANTINE NEANDERTAL}

\section{First conclusions}

Keith (1927) first presented a description of the specimen, as a contribution to a volume on the cave edited by Turville-Petre. He later included part of this description in the 1931 edition of New Discoveries Relating to the Antiquity of Man. In this work he suggested that the specimen was a young female. His age diagnosis emphasized the unfused frontal and sphenoidal sutures. Sex diagnosis was based on frontal size and facial features. Keith regarded the cranium as that of a Neandertal variant, distinguished from the European Neandertals mainly by a high but narrow forehead and an unusually broad supraorbital region (especially relative to the maximum breadth of the frontal). 
Hrdlička examined the Zuttiyeh specimen in 1927, and reviewed its morphology in his 1930 monograph (pp. 303-310). He concluded that it was male because of the prominent supraorbitals. Hrdlička also considered the specimen a Neandertal variant, specifically regarding this variety as "more advanced" than the Europeans. In comparison with the European specimens he focused on the narrower, higher forehead and the facial gracility (given his sex determination), the modern (squared) orbital shape, and the narrower nasal root, concluding that Zuttiyeh "belongs probably well forward in this group." Indeed, when discussing his opinion that the newly described Zhoukoudian E1 cranium could also be incorporated in the Neandertal paradigm, he proclaimed (p. 368):

It is not like the lowest type of the Neanderthaler, but corresponds rather to the better developed specimens of that class such as the Galilee skull [our italics].

\section{Comparison with Zhoukoudian}

This contention, because it concerned Zhoukoudian and classified one of its specimens as a Neandertal, seemed to have been particularly irritating to Weidenreich, who discussed its dismissal at length (1943:214 215). As part of his defense of the contention that the "Sinanthropus" remains were more primitive than those of the Neandertal group, he focused on the specific comparison Hrdlička had made with Zuttiyeh:

Never was a statement more astray than Hrdlička's which brought Sinanthropus into the field of the Galilee skull. How little Sinanthropus had in common with this Palestine skull has been shown by McCown and Keith (1939). In their monograph on the Mount Carmel Group, in which they include the Galilee skull, they expressly decline to compare it with Sinanthropus because of their "distant relationship."

But Weidenreich had not seen a cast (or the original specimen) of Zuttiyeh, and based his conclusions about it on the published description, and especially on the discussions in the McCown and Keith monograph. His concerns were really focused on the status of "Sinanthropus" and did not directly involve the Zuttiyeh skull. In fact, as discussed below he agreed with Keith's contention that the specimen represented an advanced $\mathrm{Ne}$ andertal variety.

As for why McCown and Keith did not include the "Sinanthropus" remains in their comparisons, it probably had little to do with the question of how near or far they might have considered the relationship of the east Asians to be. Like Weidenreich, they were not really familiar with distant, poorly published specimens. For instance, over the period when they were preparing the monograph, only a cast of the E1 adolescent was in the British Museum (or generally available). The Locus L "Sinanthropus" crania had not yet been described in detail. Thus, while they indeed did decline to use the Zhoukoudian material in their comparisons, it is unlikely that the question of whether or not they should be making explicit comparisons between Zhoukoudian and Zuttiyeh figured prominently in their considerations of how to limit the sample they would use for comparisons in their description of the Mount Carmel specimens. This omission, in other words, did not necessarily reflect a studied phylogenetic interpretation.

\section{The relation to Tabun}

In fact, McCown and Keith drew few conclusions about Zuttiyeh at all, except in the discussion of the Tabun female, in which they contended (p. 13) that Zuttiyeh is "of the same type," linked to the Neandertals by characteristics of the frontal, zygomatic, and sphenoid bones (see Table 1).

What is her [Tabun 1] relationship to the Galilee skull? We believe that they belong to the same race, the differences, so far as they are revealed from the frontal bone, malar, and sphenoid, being due to sex and not to race. (P. 265)

McCown and Keith reversed Keith's original diagnosis of female sex. Their agreement with Hrdlička's sex determination was for the same reasons as his, the emphasis on the size and robustness of the supraorbital torus (p. 256). Paradoxically, they therefore regarded the narrower forehead and greater height of the Zuttiyeh vault, the only significant differences they drew from their comparisons with the female from Tabun, as a 
TABLE 1. Comparisons abstracted from the text of the Mount Carmel monograph

\begin{tabular}{|c|c|c|c|c|}
\hline & Zuttiyeh & Skhul 5 & Gibraltar & Tabun \\
\hline Supraorbital & Earlier robust form & & Earlier form & Earlier robust form \\
\hline $\begin{array}{l}\text { Frontal height } \\
\text { above FH }\end{array}$ & High & High & Low & Low \\
\hline Frontal angle & High (64) & High (63) & Low $(55)$ & High (62.5) \\
\hline $\begin{array}{l}\text { Minimum frontal } \\
\text { breadth }\end{array}$ & Low $(97 \mathrm{~mm})$ & Low $(99 \mathrm{~mm})$ & High $(107 \mathrm{~mm})$ & Low $(98 \mathrm{~mm})$ \\
\hline $\begin{array}{l}\text { Supraorbital torus } \\
\text { overhang }\end{array}$ & Large (22 mm) & Large $(23 \mathrm{~mm})$ & Small $(11 \mathrm{~mm})$ & Small (15 mm) \\
\hline $\begin{array}{l}\text { Maximum frontal } \\
\text { breadth }\end{array}$ & Small & Small & Large & Large \\
\hline $\begin{array}{l}\text { Angle of inferior } \\
\text { zygomatic border to } \\
\text { the horizontal }\end{array}$ & $\begin{array}{l}\text { Straight, angle } \\
\text { marked }\end{array}$ & $\begin{array}{l}\text { Incipiently notched, } \\
\text { angle less marked }\end{array}$ & $\begin{array}{l}\text { Straight, angle } \\
\text { marked }\end{array}$ & \\
\hline $\begin{array}{l}\text { Body of the } \\
\text { zygomatic relative } \\
\text { to orbital pillar }\end{array}$ & Small & Small & Small & \\
\hline Zygoproptosis $^{2}$ & Slight & Slight & None & \\
\hline $\begin{array}{l}\text { Alignment of orbital } \\
\text { pillar }\end{array}$ & Straight & Straight & Moderate bending & \\
\hline $\begin{array}{l}\text { Projection of lateral } \\
\text { orbit border in } \\
\text { front of greater } \\
\text { wing of the } \\
\text { sphenoid }\end{array}$ & Greater (39 mm) & Lesser (37 mm) & Lesser $(37 \mathrm{~mm})$ & \\
\hline $\begin{array}{l}\text { Extent of lateral } \\
\text { pterygoid } \\
\text { attachment on the } \\
\text { greater wing of the } \\
\text { sphenoid }\end{array}$ & Slight & Marked & Absent & \\
\hline $\begin{array}{l}\text { Nasomalar angle } \\
\text { (M 77) }\end{array}$ & High (159) & High (156) & Low (134) & Intermediate (140) \\
\hline $\begin{array}{l}\text { Length difference } \\
\text { between glabella } \\
\text { and nasion } \\
\text { horizontals }\end{array}$ & Slight $(3.0 \mathrm{~mm})$ & Marked $(10.5 \mathrm{~mm})$ & Slight $(3.0 \mathrm{~mm})$ & Slight $(3.0 \mathrm{~mm})$ \\
\hline $\begin{array}{l}\text { Recession of nasal } \\
\text { root }\end{array}$ & Shallow & Deep & Shallow & Shallow \\
\hline $\begin{array}{l}\text { Superior internasal } \\
\text { suture }\end{array}$ & Fused & Fused & Open (in spite of age) & \\
\hline $\begin{array}{l}\text { Projection of nasals } \\
\text { anterior to the } \\
\text { frontal process of } \\
\text { the maxilla }\end{array}$ & Small & Small & Large & \\
\hline $\begin{array}{l}\text { Superior breadth } \\
\text { across nasals }\end{array}$ & Intermediate & Small & Intermediate & Very large \\
\hline $\begin{array}{l}\text { Breadth of nasal root } \\
\text { (bilachrymal) }\end{array}$ & Intermediate & Intermediate & Small & Large \\
\hline Orbit width (M 51) & Less & Slightly greater & Slightly greater & Less \\
\hline Orbit height (M 52) & Large $(37 \mathrm{~mm})$ & Small (30 mm) & Large $(39 \mathrm{~mm})$ & Intermediate $(33 \mathrm{~mm})$ \\
\hline
\end{tabular}

${ }^{1}$ The zygomatic is quartered with a horizontal line connecting the superior points on the zygotemporal and zygomaxillary sutures, and a line orthogonal to it extending from the fmo point. According to McCown and Keith, the "modern" condition is to have a large zygomatic body (the inferoposterior quarter) relative to the size of the orbital pillar.

${ }^{2}$ Zygoproptosis, according to McCown and Keith (1939:365), is the inferior projection of the masseteric attachment on the lower edge of the temporal process of the zygomatic bone. This contrasts with the straight lower border of Neandertals as described by Rak (1986).

reflection of male sex rather than of a more distant relationship.

The emphasis on a close relationship to the Tabun woman is more phylogenetically ambiguous than it might seem, since McCown and Keith clearly regard this woman as a member of the same population as the Skhul hominids:
As our investigations proceeded we encountered so many characters which linked the Skhul to the Tabun type that we were ultimately obliged to presume that we had before us the remains of a single people, the Skhul and the Tabun types being but the extremes of the same series. (P. 12)

There is no contradiction here. With a single Levant population represented in the Mount 
Carmel caves, Zuttiyeh could logically be regarded as coming closer to the "Tabun end" of the range.

McCown and Keith were far from alone in regarding Zuttiyeh as a Tabun-like Neandertal specimen. Coon (1963:567) linked Zuttiyeh to the central European Neandertals of the last interglacial and suggested that it could be a descendant of populations such as represented at Krapina and Ehringsdorf. In their description of the Amud cranium, Suzuki and Takai (1970:189) wrote that Zuttiyeh is unlike the "more advanced" Amud male in having a more continuously developed (not divided into medial and lateral elements) and thicker supraorbital torus, and in its rounded (Shanidar-like) orbital margin. They regarded the combination of a disproportionately small zygomatic and robust supraorbital as particularly Neandertal-like, and concluded that Zuttiyeh is more archaic than Amud and most closely resembles Shanidar and Tabun. Trinkaus $(1983,1984)$ also regarded Zuttiyeh as an ancestral $\mathrm{Ne}$ andertal earlier in his analyses of western Asian hominid evolution (but see below). His position was that the specimen is generally archaic and similar to the earlier of the Shanidar specimens, with specific links to the later Levant Neandertals. Comparing Zuttiyeh with Shanidar 2 and 4 (1984:285), he stated:

\footnotetext{
...these individuals all have relatively long and robust faces, but they lack the midfacial prognathism of the more recent specimens. This is reflected in high zygomaxillary angles, anterior positions of the anterior zygomatic roots, ... absence of nasion projection in Zuttiyeh 1, and angled zygomatic bones of all three. The Tabun $\mathrm{C} 1$ specimen ... may well belong to this group. (P. 281)
}

These citations are taken from publications in which the authors were not focused particularly on Zuttiyeh, and none formally analyzed the relationships of Zuttiyeh with the other Levant specimens. They seem to have been influenced by McCown and Keith's conclusion that it was Tabun-like. However, the basis for McCown and Keith's conclusions is not easy to establish because systematic comparisons were not made with Zuttiyeh in the Mount Carmel monograph either. Zuttiyeh was systematically compared to Tabun, and otherwise the specimen was discussed only briefly in numerous different and often unrelated sections.

\section{The relation to Skhul}

To better examine the data McCown and Keith dealt with, we have abstracted all of the comparisons with Zuttiyeh they presented throughout the monograph, in Table 1. These have their basis in the discussions of the three specimens Zuttiyeh was compared with Skhul 5, Gibraltar, and Tabun. We note that the sex of Skhul 5 is male, and of Tabun and Gibraltar female. Dimorphism is therefore a potential source of variation in these comparisons. Nevertheless, it is of interest that even a liberal interpretation of the comparisons in this table suggests a quite different conclusion, that Zuttiyeh shares by far the most features uniquely with Skhul 5 (9 in all) and only one uniquely with Tabun. Three features are uniquely shared with Gibraltar, and three more with both Gibraltar and Tabun. Only two features are shared uniquely with both Tabun and Skhul 5. No doubt, McCown and Keith overlooked this aspect of their work because their focus was on the Mount Carmel remains and they are unlikely to have condensed and reviewed their specific comparisons with Zuttiyeh, as we have. However, our review is hardly supportive of the conclusion that Zuttiyeh and Tabun were especially close in their relationship.

We are not the first to recognize a close relation of Zuttiyeh and Skhul hominids (although the reader should note that this "recognition" is based only on the comparisons made in McCown and Keith). Weidenreich believed that Zuttiyeh was more like Skhul 5 (1943:234) than like Tabun. He thought there were no unique links between Zuttiyeh and the Zhoukoudian hominids, and considered it a member of "the Neandertal group" (as he did Skhul 5):

It would perhaps never have entered anybody's mind
to attribute the Galilee fragment or, more recently,
the Skhul calvaria to the Neandertaloid group were
they not equipped with typical supraorbitals. This
feature is one of the most characteristic peculiarities
of all the forerunners of modern man. In Paleolithic
Man of modern type mentioned above (Cro Magnon, 
Predmosti, Upper Cave of Choukoutien-the man Obercassel may be added) the supraorbital region bulges more than in modern man, but typical supraorbitals like those developed in the Neanderthal group are missing. ( $\mathrm{P} 235$ )

In fact, Weidenreich believed there were four varieties of Neandertals (p. 237). The "Rhodesian Group," most "primitive" in his view, included only the Kabwe skull. The "Spy Group" included the European Würm Neandertals (and the Saccopastore crania). The "Ehringsdorf Group" consisted of the pre-Würm Neandertals, as well as Steinheim, Tabun, and Qafzeh (sic). Zuttiyeh and the Skhul crania comprised the fourth group, which he believed were "intermediate between the Neanderthalians and modern man." Like McCown and Keith in their interpretation of the Mount Carmel remains, Weidenreich did not conceive of these varieties as being dramatically different. This is suggested by his often stated opinion (for instance, p. 239) that "the Ehringsdorf skull comes very close to the Galilee Skull."

\section{Zuttiyeh the Neandertal}

Therefore since Weidenreich regarded Zuttiyeh as a Neandertal variant, he included the Zuttiyeh cranium in many of his comparisons. This provides the opportunity to examine some of the relationships with these earlier Asians reported by Weidenreich, the only systematic comparisons between Zuttiyeh and the Zhoukoudian remains that have ever been published to date. These are presented in Table 2. Each of the five comparisons he made showed Zuttiyeh to be similar to at least some of the Neandertals, while three of the five were unlike the Zhoukoudian sample. The only two Zuttiyeh features resembling the Zhoukoudian hominids are the distinct frontal boss and the projecting supraorbitals which are separated from the frontal squama by a deep sulcus.

While the descriptions and comparisons of Zuttiyeh from the first half of the century almost invariably lead to the conclusion that it was a Neandertal, two opinions about its relations to the other Levant populations emerged from the initial description and the Mount Carmel comparisons; some workers
TABLE 2. Comparisons involving Zuttiyeh abstracted from the text of the Zhoukoudian monograph

\begin{tabular}{|c|c|}
\hline Zhoukoudian female(s) & Zuttiyeh \\
\hline Frontal sinus small & $\begin{array}{l}\text { Large as in many } \\
\text { Neandertals }\end{array}$ \\
\hline No sphenoidal sinus & $\begin{array}{l}\text { Sphenoidal sinus } \\
\text { extending laterally to } \\
\text { the pterygoid process, } \\
\text { as in Ehringsdorf }\end{array}$ \\
\hline Distinct frontal boss & $\begin{array}{c}\text { Distinct frontal boss, also } \\
\text { in Ehringsdorf and the } \\
\text { Mount Carmel crania }\end{array}$ \\
\hline $\begin{array}{l}\text { Supraorbital tori are } \\
\text { heavy and projecting, } \\
\text { continuously connected } \\
\text { by a robustly } \\
\text { developed glabellar } \\
\text { torus, separated from } \\
\text { the anterior face of the } \\
\text { frontal squama by a } \\
\text { well defined supratoral } \\
\text { sulcus }\end{array}$ & $\begin{array}{l}\text { Same general } \\
\text { supraorbital } \\
\text { characteristics, also } \\
\text { shared with the Mount } \\
\text { Carmel crania }\end{array}$ \\
\hline $\begin{array}{l}\text { The facies cerebralis is } \\
\text { transversely small and } \\
\text { low, not exhibiting any } \\
\text { special relief }\end{array}$ & $\begin{array}{l}\text { The facies cerebralis is } \\
\text { large, both in } \\
\text { transverse and vertical } \\
\text { directions, and shows } \\
\text { relief. Gibraltar } \\
\text { resembles Zuttiyeh, } \\
\text { while the Ehringsdorf } \\
\text { and Würm } \\
\text { Neandertals resemble } \\
\text { Zhoukoudian }\end{array}$ \\
\hline
\end{tabular}

found the specimen most like the other Levant Neandertal then known, Tabun, while others regarded it as most similar to the Skhul remains. At that time this was not seen as contradictory, since as noted above McCown and Keith as well as Weidenreich regarded Tabun and Skhul as members of the same "paleoanthropic" or "Neandertaloid" sample. McCown and Keith considered Skhul and Tabun a population "in the throes of evolutionary change." In specific, they regarded it to be a Neandertal collateral to modern humans.

All who believe in evolution are agreed that Neanderthal man and modern man are descendants of a common human stock. There must have been a time in the history of that ancestral stock when individuals were undergoing differentiation along, at the least, two directions-towards the purely Paleoanthropic (Neanderthal) type and towards Neanthropic type represented by the early people of Cro Magnon. (Pp. 13-14).

Our theory ... assumes that the Mount Carmel people are not the actual ancestors of the Cromagnons but Neanderthaloid collaterals or cousins of the ancestors of that type. (P. 17). 
TABLE 3. Comparisons of Zuttiyeh morphology as abstracted from Hublin (1976)

\begin{tabular}{|c|c|c|c|c|}
\hline & \multicolumn{4}{|c|}{ Zuttiyeh is most similar to } \\
\hline & Skhul 5 & $\begin{array}{c}\text { European } \\
\text { Neandertal }\end{array}$ & Kabwe & "Sinanthropus" \\
\hline $\begin{array}{l}\text { The cranial height (from bregma to "subcerebral } \\
\text { plan") }\end{array}$ & & $\mathrm{X}$ & $\mathrm{X}$ & \\
\hline $\begin{array}{l}\text { Curvature of the frontal, high in the middle of the } \\
\text { frontal forming a frontal boss }\end{array}$ & & & & $\mathrm{X}$ \\
\hline Nasion-Bregma & & & $\mathrm{X}$ & \\
\hline Supraorbital torus & & & $\mathrm{X}$ & $\mathrm{X}$ \\
\hline Orbital height & & $\mathrm{X}$ & & \\
\hline Malar bone & & & $\mathrm{X}$ & $\mathrm{X}$ \\
\hline Nasomalar angle & $\mathrm{X}$ & & & \\
\hline Sphenoid & & & & $\mathrm{X}$ \\
\hline
\end{tabular}

These opinions became more distinct later as the framework for interpreting the Levant hominids shifted. Largely due to the work of Howell (1958), the Tabun woman came to be regarded as earlier than the Skhul hominids and her more "Neandertaloid" characteristics consequently could be explained as reflecting a difference in evolutionary stage instead of as a populational variant. With a more distinct boundary envisioned between the Neandertals of the Levant and the other Levant hominids (i.e., Skhul and Qafzeh), the issue of which group the Zuttiyeh skull more closely resembled became a more serious one.

\section{ZUTTIYEH AS EARLY "MODERN HOMO SAPIENS"}

As Tabun came increasingly to be thought of as a European-type Neandertal, without any new discoveries or significant reanalysis Zuttiyeh was shifted phylogenetically to become a non-Neandertal, which meant almost by default a unique ancestor of "modern Homo sapiens." This is how it happened.

The most important development affecting the interpretation of Zuttiyeh came decades after Weidenreich, with an accurate assessment of the position of the specimen in the Levant chronology, and eventually with the determination of an absolute date, as discussed above. The archaeological associations and the date, showed the specimen to be older than any of the other Levant crania, although curiously the recognition of greater antiquity did not reinforce the earlier case for its Neandertal status. Instead, Zuttiyeh came to be viewed as a potential ancestor either of all of the Middle Paleolithic Levant hominids or uniquely of the so-called "modern" ones, and it became increasingly clear that it was relevant to consider how it may have contributed to the later western Asian populations.

In 1976 Hublin considered this question, reviewing the information then available regarding the dating, morphology and affinities of Zuttiyeh. He agreed with Keith's initial diagnosis of female sex, and was the first to note that some of the Zuttiyeh features are more archaic than any of the other Levant specimens:

Zuttiyeh presents more archaic characters than those of the neanderthalians, which could be explained by its Riss-Wurmian (?) age. The specimen also presents characteristics that are apparently more modern. In spite of the fragmentary nature of the fossil and the problem of how to orient it, it seems to me that the majority of the characters constitute an intermediate morphology between Homo erectus and the earliest modern humans whose antecedent populations are known only from Palestine. (Hublin, 1976:9)

We summarize Hublin's detailed observations that are said to support these conclusions in Table 3, comparing Zuttiyeh to the same specimens that Weidenreich discussed in his 1943 monograph. We find it difficult to draw the same inferences that Hublin did from the data we abstracted from his text. 
As Table 3 shows, the Zuttiyeh specimen resembles both Kabwe in four out of eight features, and the Zhoukoudian crania in four out of eight features. Two of these four are the same, but for the other two resemblances the comparisons involve different, unique characteristics. These results do not support Hublin's conclusion (1976, 1983) that the specimen is transitional between Homo erectus and the "first modern humans of Palestine," because the comparisons show no special similarities to the specimen best representing the latter sample, Skhul 5. Interestingly, the results also do not support Weidenreich's contention that there are no special resemblances between Zuttiyeh and the Zhoukoudian remains. Hublin noted such resemblances, stating:

Except for orbital height, most of the "Neandertal" characters of Galilee are found in the anatomy of Sinanthropus, the best known of the Homo erectus specimens.

In fact, Hublin's observations (1976) are close to what McCown and Keith (1939) reported, which is not surprising since he relied heavily on their monograph. Yet, unlike them he finally concluded that Zuttiyeh has no special relationship to the Neandertals, and no particular relationship to Tabun (1987).

Vandermeersch (1989), who expressed a similar position on the affinity of Zuttiyeh, expanded on the details supporting the contention that Zuttiyeh should be considered uniquely ancestral to a "modern" lineage, and not ancestral to the Neandertals (1989). This is part of the support he provided for his contention that the Levant Neandertals are intrusive, refugees from European glacial conditions (1981). His analysis is summarized in Table 4 . We find Vandermeersch's analysis of characteristics to be mostly similar to ours, and only disagree with his assessment of two features. For the length of the frontal squama, we find it to be within the range of the Levantine sample and specifically similar to (or smaller than) one specimen in each subgroup (similar to Skhul 9, smaller than Amud). Secondly, our assessment is that there is no separation of the frontal torus into lateral tori and supercili-
TABLE 4. Vandermeersch's (1989) analysis of the Zuttiyeh "Modern" morphological pattern

\begin{tabular}{|c|c|}
\hline Features & $\begin{array}{l}\text { Modern Homo sapiens } \\
\text { condition in Zuttiyeh }^{1}\end{array}$ \\
\hline $\begin{array}{l}\text { Length of the frontal } \\
\text { squama }\end{array}$ & Long (125 mm) \\
\hline $\begin{array}{l}\text { Nasion-bregma chord/arc } \\
\text { index }\end{array}$ & High: 90.4 \\
\hline $\begin{array}{l}\text { Lateral thinning of } \\
\text { brow-ridge }\end{array}$ & $\begin{array}{l}\text { Exists (cf. Skhul } 4, \\
\text { Predmostí 3) }\end{array}$ \\
\hline $\begin{array}{l}\text { Orientation of the frontal } \\
\text { squama }\end{array}$ & Set vertically \\
\hline $\begin{array}{l}\text { Separation of browridge } \\
\text { and frontal squama }\end{array}$ & By supratoral sulcus \\
\hline $\begin{array}{l}\text { Minimum frontal width } \\
\text { Neandertals) }\end{array}$ & $\begin{array}{l}\text { Low (cf. Skhul 5, } \\
\text { Předmostí, unlike }\end{array}$ \\
\hline Orientation of nasion & $\begin{array}{l}\text { Set back very little from } \\
\text { the glabella }\end{array}$ \\
\hline Nasal notch & $\begin{array}{l}\text { Very weak (unlike } \\
\text { Neandertals) }\end{array}$ \\
\hline Maximum frontal width ${ }^{3}$ & $\begin{array}{l}\text { Smaller than } \\
\text { Neandertals }\end{array}$ \\
\hline Frontal sinus & $\begin{array}{l}\text { Differently shaped and } \\
\text { thinner than } \\
\text { Neandertals }\end{array}$ \\
\hline Nasal bones & $\begin{array}{l}\text { Flat, and not shaped as } \\
\text { Neandertals }\end{array}$ \\
\hline Orbits & $\begin{array}{l}\text { Rectangular (wider than } \\
\text { high) }\end{array}$ \\
\hline Zygomatic bone & $\begin{array}{l}\text { More robust than } \\
\text { Neandertals }\end{array}$ \\
\hline $\begin{array}{l}\text { Position of zygomatic } \\
\text { body }\end{array}$ & $\begin{array}{l}\text { Anteriorly facing unlike } \\
\text { Neandertals }\end{array}$ \\
\hline
\end{tabular}

${ }^{1}$ By "Modern Homo sapiens," we believe that Vandermeersch actually means "non-Neandertal." He does relate these features to what he regards as "proto-Cro-Magnons" (Skhul and Qafzeh specimens) and to at least a few of the early post-Neandertal Europeans (Předmosti 1 and 3). However, by not comparing to other groups it is unclear whether these uniquely link the specimens he compared. Vandermeersch also notes Neandertal-like features in Zuttiyeh such as the large supraorbital torus or robust zygomatic. These features are com pared with the Amud 1, Shanidar 1 and 2 , and sometimes Tabun 1 in his analysis.

${ }^{2}$ On the left side of the face there is a classic continuous supraorbital torus. On the right side a healed wound is present, perhaps contribut ing to the separation of the supraorbital into a supercilliary arch and trigone by a shallow supraorbital groove.

${ }^{3}$ Maximum frontal length in Zuttiyeh is also smaller than "Proto-CroMagnons" and "Cro-Magnons," except for Qafzeh 9 and Skhul 5, according to Vandermeersch.

ary arches-see our discussion of the specimen, and Table 5.

Vandermeersch stated that the many "modern Homo sapiens-like" features shared by Zuttiyeh and the later Levant specimens from Skhul and Qafzeh provide evidence of a single lineage. In contrast, because only a few "Neandertal-like" features are shared by Zuttiyeh and the Amud and Tabun specimens, there is no closeness of relationship or corresponding intraspecies clade, in his view. Therefore he did not envision Zuttiyeh as a common ancestor for two 
TABLE 5. Distribution within the Levant hominids of nonmetric features shared by Zuttiyeh and the Zhoukoudian crania ${ }^{1}$

\begin{tabular}{|c|c|c|c|c|c|c|c|c|c|}
\hline & \multirow[b]{2}{*}{ Tabun } & \multirow[b]{2}{*}{ Amud } & \multicolumn{4}{|c|}{ Qafzeh } & \multicolumn{3}{|c|}{ Skhul } \\
\hline & & & 3 & 5 & 6 & 9 & 4 & 5 & 9 \\
\hline Frontal curvature & $\mathrm{O}$ & $\mathrm{X}$ & - & - & $\mathrm{X}$ & - & $\mathrm{O}$ & 0 & 0 \\
\hline Narrow boss & $x$ & 0 & $\mathrm{O}$ & $\mathrm{x}$ & $\mathrm{O}$ & $\mathrm{O}$ & $\mathrm{O}$ & $\mathrm{O}$ & - \\
\hline Short temporal notch & - & 0 & - & - & $\mathrm{X}$ & $\mathrm{X}$ & 0 & 0 & - \\
\hline $\begin{array}{l}\text { Supratoral sulcus: size and } \\
\text { morphology }\end{array}$ & $\mathrm{X}$ & $\mathrm{O}$ & $\mathrm{O}$ & $\mathrm{X}$ & $\mathrm{X}$ & $\mathrm{O}$ & 0 & $\mathrm{X}$ & $\mathrm{X}$ \\
\hline Glabella depression & $\mathrm{X}$ & $\mathrm{O}$ & $\mathrm{X}$ & - & $\mathrm{O}$ & - & $\mathrm{X}$ & $\mathrm{O}$ & - \\
\hline Flat nasal root & $\mathrm{X}$ & $\mathrm{O}$ & $\mathrm{X}$ & - & 0 & - & $\mathrm{X}$ & $\mathrm{O}$ & - \\
\hline Nasal bones transversely flat & - & 0 & 0 & - & 0 & - & - & 一 & - \\
\hline Tubercle on zygomatic anterior face & - & $\mathrm{X}$ & - & - & $\mathrm{X}$ & $\mathrm{X}$ & $\mathrm{O}$ & 0 & - \\
\hline $\begin{array}{l}\text { Anterolateral orientation of } \\
\text { zygomati }\end{array}$ & - & $\mathrm{O}$ & - & - & $\mathrm{X}$ & $\mathrm{X}$ & $O$ & 0 & $\mathrm{X}$ \\
\hline $\begin{array}{l}\text { Unangled superior nasal bones } \\
\text { (vertical orientation) }\end{array}$ & - & $\mathrm{O}$ & $\mathrm{X}$ & - & $\mathrm{O}$ & - & - & 一 & - \\
\hline
\end{tabular}

${ }^{1}$ The character states are defined by the shared features of the Zuttiyeh-Zhoukoudian comparisen and evaluated for the purpose of this comparison and not on an absolute scale. Thus, the table does not provide an in dependent definition of frontal curvature, but rather reports that Amud and Qafzeh 6 have frontals that are curved in the sagittal plane in a manner similar to the frontal curvature common to Zuttiyeh and the Zhoukoudian sample. $\mathrm{X}=$ present; $\mathrm{O}=$ absent; $-=$ part not preserved.

distinct Levantine demes, but rather considered it a unique ancestor for only one of these.

Vandermeersch recognized that there are numerous regional features shared among all of the Levant specimens, including Zuttiyeh. However, he emphasized the unique links between this early specimen and the Skhul/Qafzeh remains in his analysis of evolution in the region. In summarizing Vandermeersch's observations, Table 4 shows that his model of a "Zuttiyeh-modern Homo sapiens" lineage is based on the "non-Neanderthal like" features. This model therefore assumes that "non-Neandertal-like" must mean more "modern-like" and synapomorphic. The lack of a similar set of shared unique resemblances linking Zuttiyeh and the Levant Neandertals is significant in Vandermeersch's phylogenetic reconstructions. Thus, according to Vandermeersch's phylogeny, the few "Neandertal-like" features in Zuttiyeh must be interpreted as plesiomorphic, and their presence is explained as a consequence of Zuttiyeh's more ancient age.

But if true for some of the Levantine folk, this interpretation must be true for all, and the fact is that this interpretation does not validly describe character states in the Levant. Why should the Neandertal-like features found in the Levant be considered plesiomorphic, given the fact that they are ubiquitous among Levant populations that are later than Zuttiyeh, for instance Amud and Tabun, but are only rarely and sporadi. cally present in earlier hominids? What makes this problematic is the fact that the shared unique features of a hypothetical modern Homo sapiens clade that are defined by the assumption that the Neandertal-like features are plesiomorphic, are the very features that have the best case for geologic precedence. If geologic precedence is the criterion for plesiomorphy (an assumption Vandermeersch is willing to make in discarding the similarities of Zuttiyeh and the later Neandertals), then the attributions of character states must be reversed. In this case, Zuttiyeh and the Skhul/Qafzeh specimens would have to belong to a "modern clade" that is not defined by synapomorphies!

We agree with the suggestion that "it is possible that some of the facial features that separate [Zuttiyeh] from Neandertal specimens are plesiomorphies rather than modern apomorphies" (Stringer et al., 1984:118).

\section{ZUTTIYEH AS A GENERALIZED LEVANT HOMINID}

The phylogeny suggested by Hublin and Vandermeersch takes on added significance with the contention that the split between Levant Neandertals and what they (following Howell, 1958) call "proto-Cro Magnoids" 
is at the species level (Gould, 1989; Rak, 1990; Stringer, 1990). But not all authors believe that there is a split in the Levant hominids, instead accepting Howell's (1958) model of a continuous evolving human line in the Upper Pleistocene of western Asia. Others, accepting a split, believe it occurred later than Zuttiyeh. If there is no split, or if it postdates Zuttiyeh, there is no problem of which side Zuttiyeh lies on.

Trinkaus, after first regarding Zuttiyeh as an ancestral Neandertal, later came to consider it as a generalized ancestor of all the more recent west Asian hominids, as he did the specimens he considered it most similar to, Shanidar 2 and 4 . He believes (1989:45) "Zuttiyeh ... preserve[s] no uniquely derived (autapomorphous) features of either modern humans or of Neandertals." However, he bases this assessment on a number of comparisons we believe to be incorrect (also see Trinkaus, 1991). These include the claim that its frontal morphology is archaic (compared to what? The frontal is similar to the Zhoukoudian hominids but quite unlike those from Sangiran), the assertion that frontal is "clearly distinct from those of early modern humans" (in fact it is very similar to Qafzeh 3, and see below), and the assessment that its anterior orbital projection is particularly elevated relative to the cranial base.

Similarly, Smith (1985) regards Zuttiyeh as an early (or the earliest) member of the Levant hominid line, ancestral to all of the later hominids from the region and therefore not uniquely ancestral to either a modern or a Neandertal lineage. In a principal components analysis of the Levant sample (Simmons et al., 1991) it was concluded that Zuttiyeh is not particularly similar to the Shanidar sample, but is most similar to Amud. These authors show that

arguments for a greater phenetic or cladistic similar-
ity between Zuttiyeh and Skhul/Qafzeh than between
Zuttiyeh and the Levantine Neandertals are simply
not supported by available data... . Zuttiyeh is prim-
itive compared to both Levantine Neandertals and
the Skhul/Qafzeh hominids

Stringer (1985:294) would seem to concur, concluding that Zuttiyeh "does not appear to this author to be transitional between archaic and modern humans."
Finally, in a recent study Rak (1986) suggested that the Zuttiyeh face fit his model for a "generalized (i.e., unmodified) face" (p. 153). By "generalized face" Rak meant the facial morphology "shared . . by many primates, including modern humans and fossil species of the genus Homo. He characterized the "generalized" face in great detail, but in so far as the regions preserved in Zuttiyeh are concerned only two of the criteria can be applied:

a peripheral region oriented approximately on the coronal plane with the infraorbital plates facing forwards. Their surface slopes down and slightly backwards.

According to Rak these specifics are shared with the Zhoukoudian faces, which if true would provide a link between Zhoukoudian and Zuttiyeh lacking phylogenetic significance since it would be based on plesiomorphies.

We concur that there is such a link, but question whether it is actually established on features plesiomorphic (or "generalized") for Homo. Our concern is based on two facts. First, we have discussed (and discuss below) a number of additional similarities between Zuttiyeh and the Zhoukoudian remains that Rak does not include in his concept of the "generalized" face. Many of these are unique to Asian Homo, even if the two features Rak discussed are not. Second, we believe that of all the features Rak discussed, the two that pertain to Zuttiyeh actually are not "generalized" in the sense he meant. For instance, the male face from Sangiran 17 has infraorbital plates that slope down and markedly forwards. If one believed there was such as thing as a single "generalized" facial pattern for Homo, the Indonesian specimen is much more complete than any from Zhoukoudian and would be at least as good a candidate for ascertaining the "generalized" morphology character state. Further, if we were to use geologic precedence to establish "generalized," among the earlier pre-dispersal faces of Lower Pleistocene Africans, ER 3733 resembles the Zhoukoudian reconstruction in these two features, but the infraorbital plates of ER 3883 have an anteroinferior orientation (similar to Sangiran 17) and a lateral orientation to the peripheral aspects of 
the plates that begins in a more medial position than any of the Asian Homo faces discussed above. One of us (MHW) has studied the original specimen and asserts that this anatomy is not the result of distortion in the infraorbital region. We conclude that there is no single pattern of plesiomorphic (or "generalized") infraorbital anatomy that can be established within known specimens of Lower and earlier Middle Pleistocene Homo.

In sum, we reject the contention that the relation of the Zuttiyeh face to the Zhoukoudian specimens is irrelevant to phylogeny because it is based on plesiomorphic features.

\section{WHY SO MANY OPINIONS?}

Historically it is clear that virtually every opinion possible has been expressed with regard to Zuttiyeh's phylogeny, with different hypotheses often expressed by different combinations of the same authors [for instance, compare Stringer (1985), Hublin (1976), Vandermeersch (1989), and Stringer et al., (1984)]. Among those who believe there were two lines, Zuttiyeh has been allocated to each side. In the past, whether Levant hominids were regarded as evolving toward Neandertals (of the sort found in western Europe), or toward post-Neandertal European populations such as seen at CroMagnon, Zuttiyeh has been considered to be part of each process. More currently, for those who believe that early modern humans appear first in the Levant, and that the Levant Neandertals are later refugees from glaciated Europe, Zuttiyeh is seen as the unique ancestor of the modern humans. For others who regard the Levant sequence as reflecting regional continuity and the gradual evolution from Neandertals to modern humans, Zuttiyeh is seen at its base. While the question of two Levantine lineages has been critical in evaluating Zuttiyeh, we believe that the morphology of Zuttiyeh cannot be used to determine the converse, whether one or two lineages are represented by the later Levantine hominids. This could only be a useful approach if there were clearly two subsequent samples of Levant hominids defined by two different sets of apomorphic features, and if one of these were linked to synapomorphies in Zut- tiyeh. Such a phylogenetic model, while possible, has never been suggested for the Levantines.

If nothing else, it is evident from the above that the morphology of the Zuttiyeh specimen is neither an obvious reflection of evolutionary grade nor of cladogenesis. We question why so many different interpretations of the features of Zuttiyeh have been retained? In our opinion, its phylogenetic position in the region and the explanation of why there has historically been so much confusion about it, is not a simple consequence of incompleteness. It is, at least in part, a consequence of confusing grade and intraspecies clade features.

\section{EAST ASIAN EARLIER MIDDLE PLEISTOCENE FEATURES IN ZUTTIYEH}

It is this suggestion that we will explore below. If a confusion of grade and intraspecies clade results from analyzing the later Levant specimens, perhaps information about earlier hominids would be useful. Such information must come from other regions since Zuttiyeh is the earliest Levantine cranium. We find that visual inspection, if not the conclusions that can be drawn from Hublin's (1976) comparisons, indicate the possibility of a special relationship with the earlier east Asian folk. Therefore, we begin by examining the relationship of this specimen with the remains from Zhoukoudian. If this comparison shows that Zuttiyeh's unique features can be linked with these much earlier east Asians, by definition they cannot be considered modern apomorphies.

[As an aside, we do not choose to also compare Zuttiyeh with later Middle Pleistocene Asians (Dali, Maba, Jinniushan, Yunxian) for several reasons. This comparison raises different issues that we intend on covering in a forthcoming paper and which do not effect the question of a link between Zuttiyeh and Zhoukoudian. Moreover, three of the four specimens in question are not yet available for a detailed study that can be published (M.H.W.'s observations, however, suggest that these fit the model quite well). Finally, it is quite possible that Zuttiyeh is of comparable age to these specimens, which would make the question of potential ancestry irrelevant.] 
We believe that the obvious resemblance of Zuttiyeh to the frontofacial portions of the Zhoukoudian specimens is a reflection of an intraspecies clade relationship which has never been examined systematically-this is the hypothesis we propose to test. Perhaps this hypothesis was never tested before because Weidenreich was so adamant in denying any special relation existed, but we believe Weidenreich's opinion was more in response to Hrdlička's claim that "Sinanthropus" was a Neandertal variant, than the result of any systematic analysis of Zuttiyeh on his part. In our view, the intraspecies clade relationships reflected in the non- $\mathrm{Ne}$ andertal features of the western Asian samples have been misinterpreted to suggest a "modern Homo sapiens" grade (the assumption that non-Neandertal means modern), when their explanation is actually quite different. It is also possible that the hypothesis has been ignored because of potentially confusing descriptions of character states in fossil hominids. For instance, Habgood (1992:279) describes Zuttiyeh as exhibiting a Mongoloid-like "flat upper face with forward jutting malar bones," but he also attributes this morphology to specimens such diverse as Bodo and Sangiran 17. Such attributions suggest a quite different definition of a Mongoloid-like flat face than the classic morphological one (cf. Coon, 1963) we have applied here to the incomplete Zuttiyeh face (see below).

Here we take several approaches to the question of whether the Zuttiyeh morphology includes those elements of the Zhoukoudian frontofacial complex that can be expected in the anatomical regions it preserves (Weidenreich, 1943; Coon, 1963; Wolpoff et al., 1984). Most of the comparative information comes from ZKT L2 and L3, since few other specimens preserve parts corresponding to Zuttiyeh, and no other east Asian earlier Middle Pleistocene remains preserve comparable elements of the face. Limited comparisons are also made with the less complete Zhoukoudian vaults, Gongwangling (Woo, 1966), and Hexian (Wu, 1985; Wu and Dong, 1982; Etler, 1990). To examine the potential refutations for this hypothesis we decline to use either a discrimination type analysis or a clustering ap- proach because these are likely to do little more than continue the confusions of grade and intraspecies clade features that already are well published (see above, and for a recent example Holt and Waddle, 1991). Moreover, we have not attempted to once again fully describe Zuttiyeh. Rather we focus on two ways of viewing the problem. These are the questions of (1) how Zuttiyeh fits into comparisons between east Asian earlier Middle Pleistocene remains and the later Levant crania, and (2) whether comparisons with other geographic regions show the features that link Zuttiyeh and the east Asians to be regionally unique.

\section{METRIC ANALYSIS}

If our hypothesis is correct, we would expect many if not most of the differences between the later Levant crania and Zuttiyeh to place Zuttiyeh in the direction of the Zhoukoudian frontofacial morphology. Conversely, if Zuttiyeh does not fit between these east Asians and the subsequent Levant folk, it would argue against the contention of a unique phylogenetic link connecting the Upper Pleistocene hominids from the Levant and the earlier east Asians.

In our metric analysis of Zuttiyeh, we examined 77 chord and arc measurements of the specimen and compared these with the corresponding data for the other Levant crania (Amud, Tabun, and the full samples from Skhul and Qafzeh). All of these measurements were taken by one of the authors (M.H.W.) on the original Levant specimens, using the same techniques. The east Asian Zhoukoudian measurements were taken by the same author on the primary cast set at the American Museum of Natural History, and on the original H3 specimen in Beijing. The two other earlier Middle Pleistocene crania from the region cannot be included in the metric analysis. Gongwangling preserves virtually nothing that remains in Zuttiyeh except the frontal and superior nasal, and this is far too distorted for accurate measurements. Hexian is not yet available for measurements.

The most obvious conclusion we found in the preliminary univariate metric comparisons is an unsurprising one; for the vast majority of linear measurements and indices, 


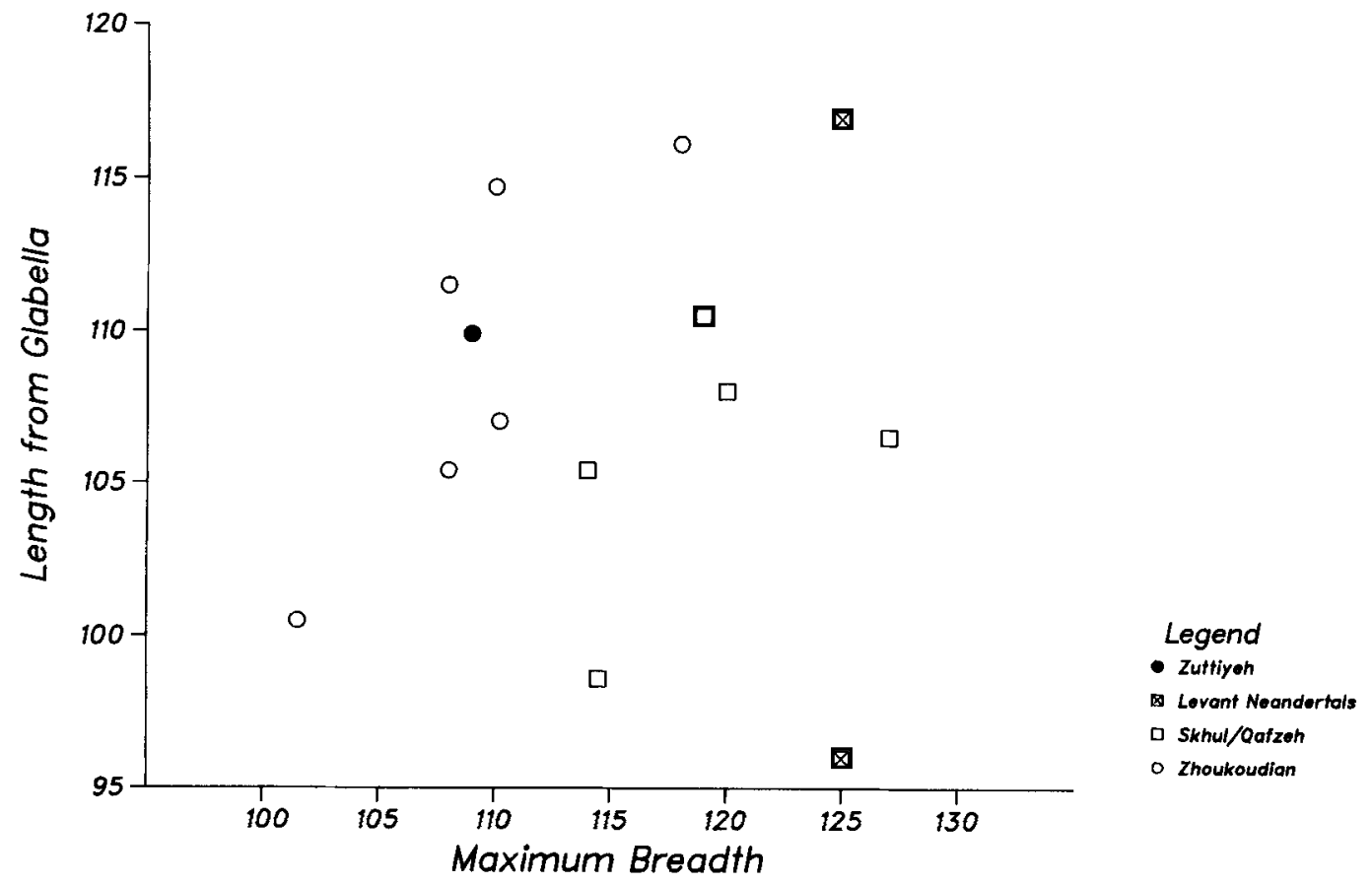

Fig. 1. Relative size of the Zuttiyeh frontal bone in the Zhoukoudian and Levant samples.

Zuttiyeh closely resembles the other Levant crania (especially the Tabun and Qafzeh 3 females), falling within the range of variation of the Levant sample. Moreover, for virtually all of these measurements the Levant samples themselves overlap, so that at least as far as the parts preserved on the Zuttiyeh fragment are concerned, few details separate the so-called "Levant Neandertals" from the "moderns." The implications of a similar observation were discussed at length by McCown and Keith (1939) and Dobzhansky (1944), who recognized a close relationship between the Skhul and Tabun remains. In our analysis, we find no purpose in focusing on the features that overlap between the post-Zuttiyeh populations of the Levant.

Only a few metric features were found to separate Zuttiyeh from the other Levant crania, although these do not necessarily distinguish Levant samples from each other. We review all of these in the scatter plots shown in Figures 1 through 3. The distinguishing features are all associated with the frontal bone. No metrics of the Zuttiyeh zygomatic, or of the middle face, clearly separate the specimen from the other Levant crania. Zuttiyeh's uniquenesses involve elements of frontal size (Fig. 1), frontal shape (Fig. 2), and the dimensions of the lateral aspect of the supraorbital torus (Fig. 3).

The unique aspects of frontal bone size can be seen in the comparison of the bone's sagittal length from glabella plotted against maximum frontal breadth (Fig. 1). The Zuttiyeh bone is narrower than any other of the Levant crania, but longer than all but Amud (it is about the same length as Skhul 9). The scatter plot shows Zuttiyeh totally within the Zhoukoudian cluster. In terms of size, then, the Zuttiyeh frontal is unlike the later Levant crania and indistinguishable from the Zhoukoudian remains.

The distinguishing aspects of frontal shape (Fig. 2) are found in the frontal curvature (arc/chord) index as calculated from nasion, and the relative projection of nasion anterior to the bi-fmt line (the relative projection is an index of the nasion projection and the nasion-bregma length). These pro- 


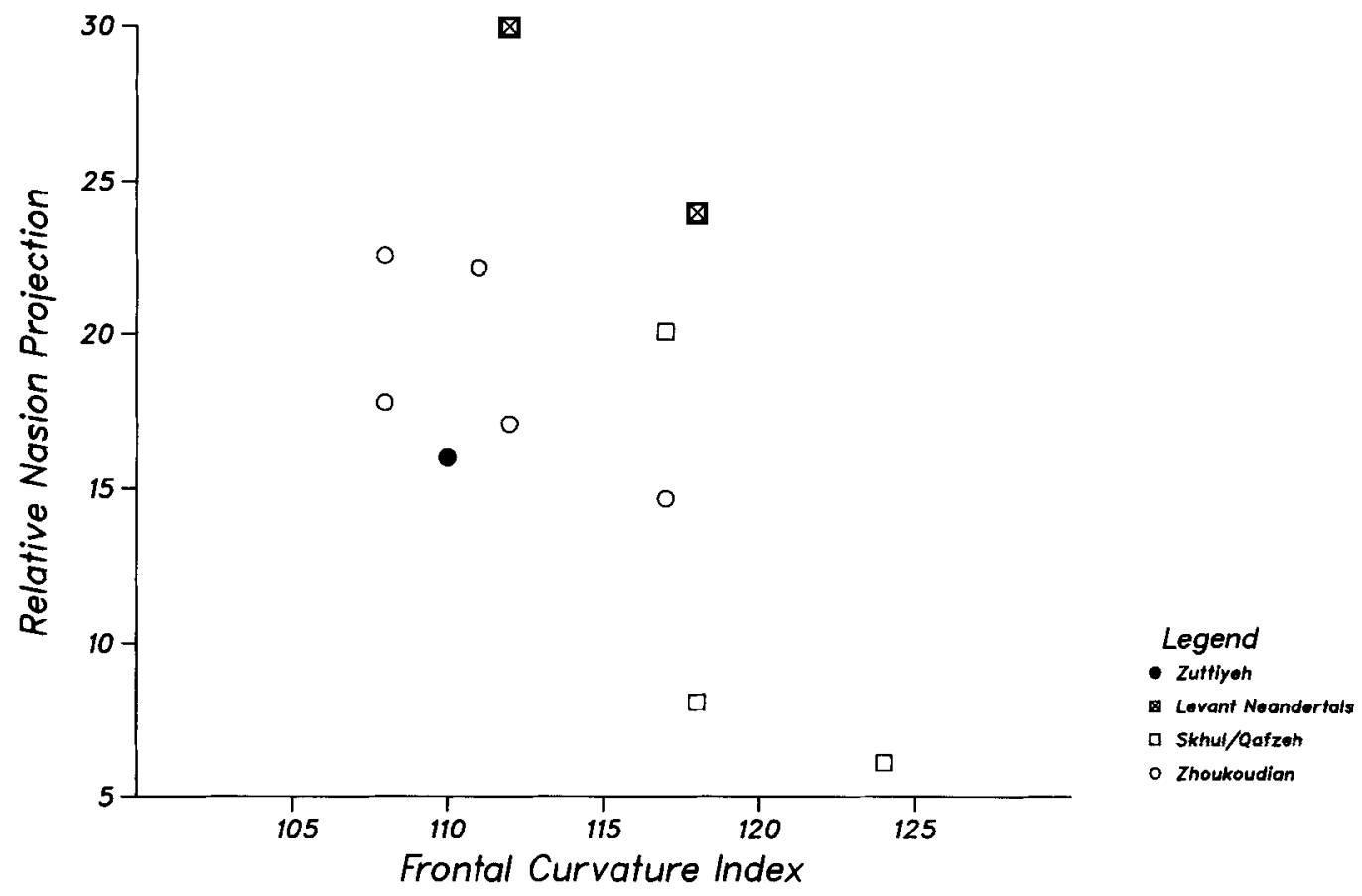

Fig. 2. Relative shape of the Zuttiyeh frontal bone in the Zhoukoudian and Levant samples.

vide measures of the frontal curvature and of what we describe as the flatness of the upper face. [This is not the same as a much more widely cited measure, facial flatness, which is a description of the zygomaxillary region that is incomplete in this specimen.] Zuttiyeh has a relatively uncurved (i.e., sagittally flattened) frontal, very flat as compared with the Levant Neandertals. In the paracoronal plane, its upper face is also transversely flat. Taken together, the small nasion projection and the large frontal curvature measures fall very close to the Zhoukoudian cluster. We note that in contrast, upper facial flatness is not a European Neandertal feature (see Wolpoff et al., 1981; Trinkaus, 1991), just as it does not characterize the Levant Neandertals. The presence of transverse upper facial flatness is not necessarily a marker of "modern humans" either, since the Zhoukoudian specimens, and as far as one can determine visually Gongwangling and Hexian as well, also have flat upper faces.

Supraorbital dimensions of Zuttiyeh closely resemble those of the other Levant crania in medial and mid-orbital positions, and indeed the Levant hominids cannot be separated into different samples on the basis of these measurements. However, in its most lateral aspect (Fig. 3) Zuttiyeh is vertically thinner than any specimen except Amud, but its projection anterior to the endocranial surface is greater than all of the Levant crania. It lies between the Levant frontals and the Zhoukoudian sample in the scatter plot showing the relation of these two variables.

Perhaps the most unexpected result of focusing on the features for which Zuttiyeh is unique is that these seem to either completely align the specimen with the Zhoukoudian sample, or show Zuttiyeh to be intermediate between these earlier east Asians and both of the later Levant samples.

\section{MORPHOLOGICAL ANALYSIS}

To further examine the possibility of a link between Zuttiyeh and the earlier east Asians, we undertook a series of morphological comparisons. Our conclusion, as detailed below, is that the morphological simi- 


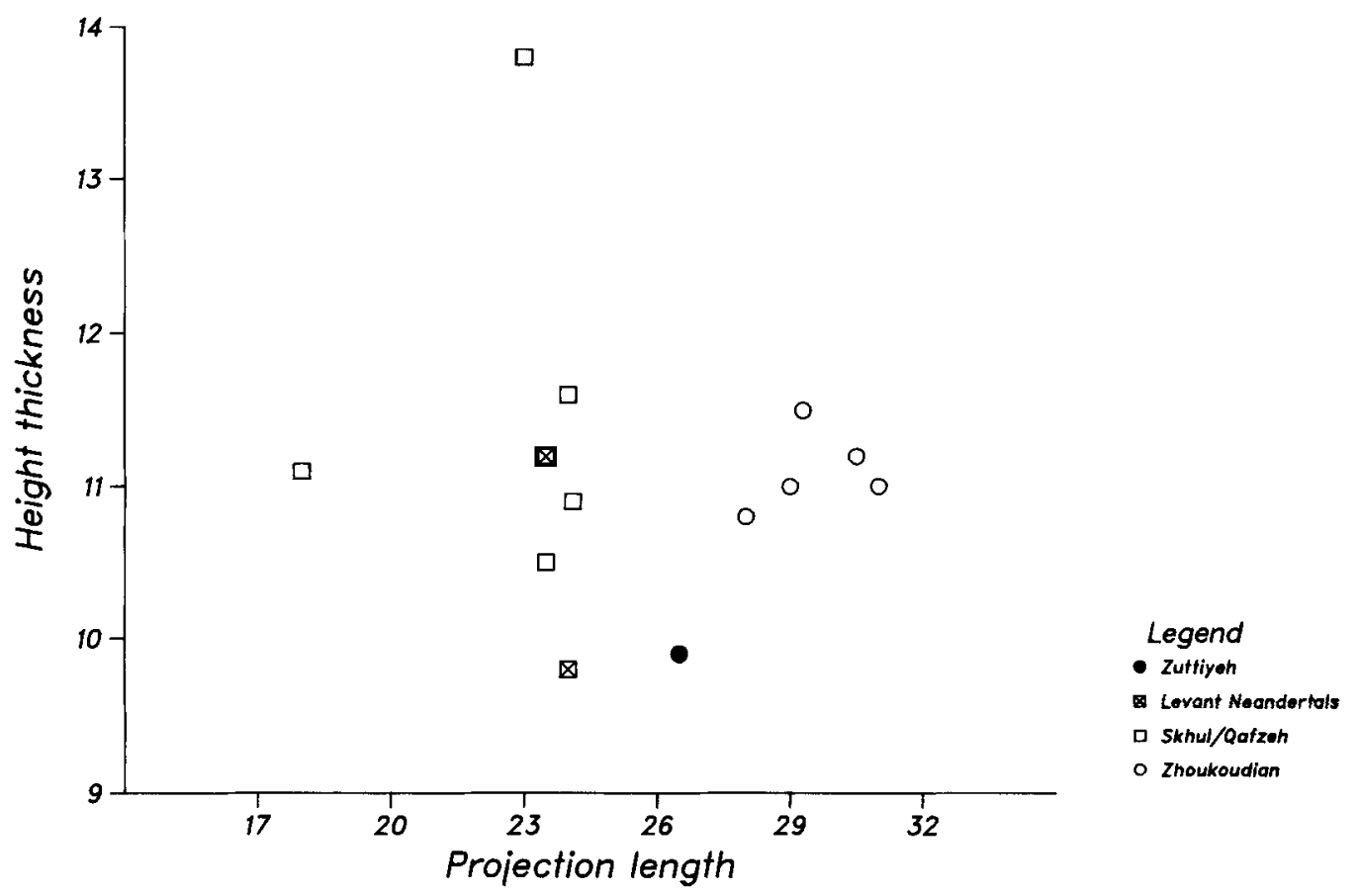

Fig. 3. Relative dimension of lateral supraorbital torus of the Zuttiyeh frontal bone in the Zhoukoudian and Levant samples.
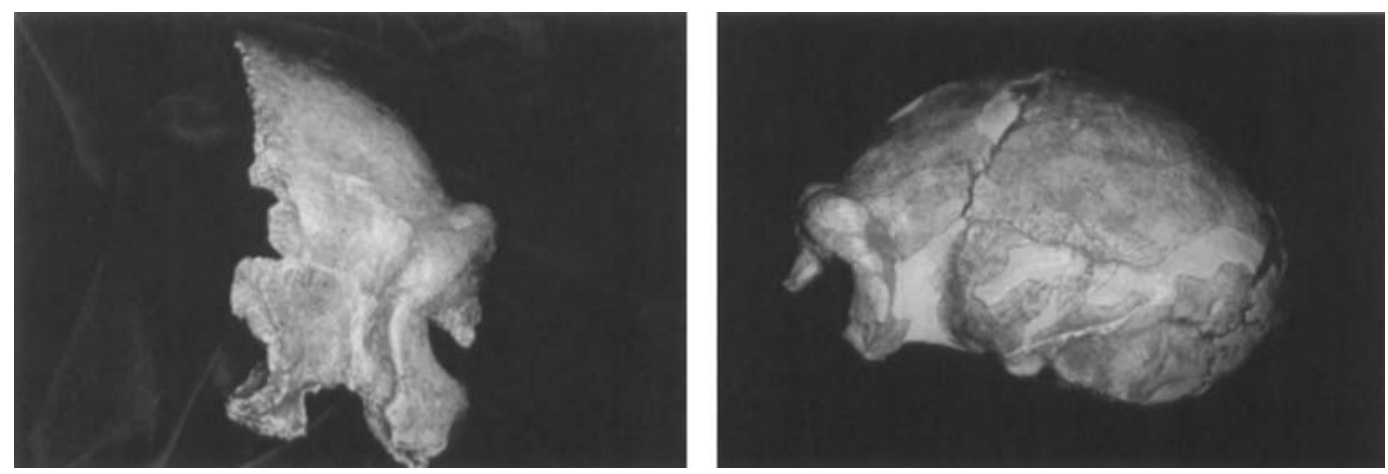

Fig. 4. Zuttiyeh (left) and a cast of Zhoukoudian 12 in lateral view, not to the same scale.

larities of Zuttiyeh with the Zhoukoudian crania-and, where comparisons are possible, also with Gongwangling and Hexianare striking (Figs. 4, 5). There are obvious similarities in the frontal shape (curvature-also as indicated in the metric comparisons-and narrowness of the centrally located boss), although unlike the Zhou- koudian specimens and Hexian there is no frontal keel and the squama thickness is generally less. The temporal notches are equally short in an anteroposterior direction, while the internal wall is more vertical in Zuttiyeh than in the Zhoukoudian specimens. The size, shape, and depth of the well excavated supratoral sulcus is identical to 

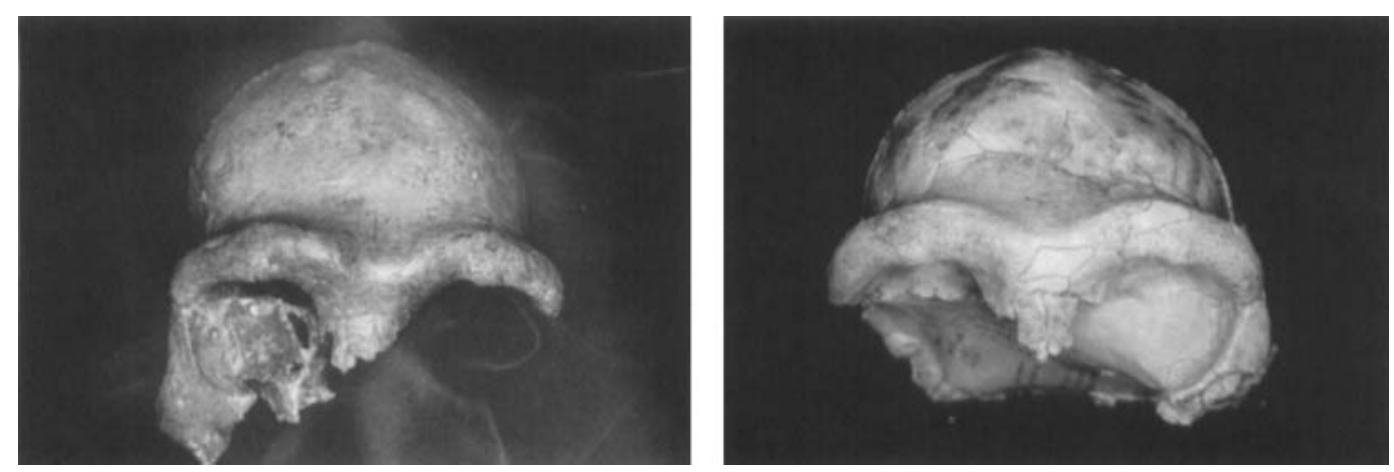

Fig. 5. Zuttiyeh (left) and a cast of Zhoukoudian 12 in frontal view, not to the same scale.

all of the Asian specimens, and this identity extends to the transversely flattened supranasal region.

A suite of upper facial features is shared with all of the east Asian specimens. For instance, Zuttiyeh resembles all in exhibiting a rounded superior orbital contour and supraorbital configuration above it. Glabella is not prominent; in fact, from above the central supraorbital region is slightly depressed at the midline. Directly below glabella, when preserved the superior nasal region is extremely flattened, both above and below the frontonasal suture where the nasal bones of Zuttiyeh are transversely as flattened as ZKT D1 and L1, and even flatter than H3, L2 (which is identical to Gongwangling), and L3. The Zuttiyeh nasals are also similar to the above in their lack of a sagittal keel, the very flat (undepressed) nasal root, and the vertical orientation of the preserved superior aspect of the nasal bones. The zygomatic is somewhat more laterally oriented than in L3, and is more similar to the $\mathrm{L} 2$ reconstruction in its anterolateral angulation (for instance as seen from above). It differs from a number of specimens sometimes described as "flat-faced," but whose flatness only involves the anterior maxillary face, contrasting with a much more laterally oriented zygomatic which sharply angles along the zygomaxillary suture. In Zuttiyeh the zygomatic contributes significantly to midfacial flatness of the classic Mongoloid form (cf. Coon, 1963).
Thus, we interpret the orientation of the medial aspect of this bone as reflecting marked mid-facial flatness similar to that in the Gongwangling midface (in so far as it is preserved) and even flatter than the ZKT L2 maxilla, and we question why Keith was able to describe this region as "Neandertallike." The isolated L1 zygomatic, a male, is more robust than Zuttiyeh where comparable. However, Zuttiyeh is similar to it in the marked development of a tubercle along the inferior third of the anterior face, above the tuberosity for the masseter attachment (which is missing on Zuttiyeh).

On the whole, Zuttiyeh shares many features with the comparable portions of Gongwangling, Hexian (although there is not much basis for comparison) and the Zhoukoudian crania, most of which are regionally specific to this north China sample. Most striking is the contribution of the superior orbital border, the nasal root and region just above it, and the zygomatic, to the combination of upper facial flatness and flatness of the mid-face described above, as these combine features that are most common in living Mongoloid populations and (those who we perceive to be) their ancestors. We do not mean to imply that Zuttiyeh is no more than a west Asian version of the Zhoukoudian folk, for there are differences as well as the similarities we mention above. Never the less, we find that the contention of a fairly close relationship between these is well supported by the morphological data and not at 
all contradicted by the revised Middle Pleistocene age estimate.

\section{OTHER REGIONAL COMPARISONS}

The significance of the morphological comparisons is linked to the distribution of these features in other samples that could, alternatively, be ancestral to Zuttiyeh. Such samples are found in Europe and Africa.

\section{Lower Pleistocene Africans}

The earliest Homo sapiens remains are African-this is where to the best of our knowledge the species originated at the beginning of the Pleistocene. Some workers [for instance, Simmons et al. (1991)] have suggested that the flat facial morphology shared by Zuttiyeh and the Zhoukoudian remains is also shared by the Lower Pleistocene Africans. If true, such a similarity could potentially remove facial flatness from the suite of derived characters uniquely linking Zuttiyeh with the Zhoukoudian specimens (although it would not remove the other shared unique features from this list). In fact, however, it is not the case. In ER 3733 and 3883 there is variability in the orientation of the zygomatic, as we describe above, but in both specimens the bulk of the zygomatic's face is oriented in a much more lateral direction than in Zuttiyeh. We believe that the description of these early Africans as "relatively flatfaced" is not accurate and does not match our delineation of east Asian facial flatness detailed above.

These Lower Pleistocene Africans are common ancestors to both Zuttiyeh and Zhoukoudian. The absence of Mongoloidlike middle and upper facial flatness in this sample supports the contention of a Zhoukoudian-Zuttiyeh relationship, but because the sample is much earlier it does not address the issue of whether this relationship is particularly unique. For this reason, it is useful to examine the Middle Pleistocene humans of Europe and Africa, since they represent populations who may be different potential ancestors of Zuttiyeh, but not of their east Asian contemporaries or predecessors from Zhoukoudian. We recognize the possibility that one or both of these samples is the same age as Zuttiyeh, which would make the question of even potential ancestry irrelevant.

\section{Middle Pleistocene Europeans}

Most of the frontofacial features Zuttiyeh shares with the Zhoukoudian sample do not on the whole characterize Middle Pleistocene samples from other areas, although they are occasionally found in isolation. For instance, considering the European sample, with the possible exception of frontal narrowing, our comparisons show that none of the metric distinctions of Zuttiyeh or its specific detailed morphological similarities to the Zhoukoudian remains characterize Steinheim or Arago 21 (contra Wolpoff 1980, who reported similarities between Zuttiyeh and Steinheim in a comparison that was not metric and did not include the Zhoukoudian remains). Nor are these metric and morphological distinctions linking Zuttiyeh and the Zhoukoudian hominids shared with the male vault from Petralona. If these members of the Middle Pleistocene European intraspecies clade are regarded as an outgroup for comparative purposes, the similarities Zuttiyeh shares with the Zhoukoudian crania are clearly highlighted as being different and thereby unique.

\section{Middle and Early Upper Pleistocene Africans: the "Eve" theory}

With regard to the later African remains, according to some hypotheses (for instance, the "Eve" theory) Middle and/or early Upper Pleistocene Africans are uniquely ancestral to all modern humans (Stringer, 1990; Stringer and Andrews, 1988). Presumably this means that Middle and/or early Upper Pleistocene Africans are related to Zuttiyeh, unless this specimen is not thought to be ancestral to the Skhul/Qafzeh hominids-a contention no author has supported. We, with others, accept the hypothesis of this ancestral relationship. Therefore the demands of the "Eve" theory are relevant to the interpretation of Zuttiyeh. If Zuttiyeh is not a Neandertal, but is ancestral to the Skhul/Qafzeh hominids, it must be closely related to the Middle and/or early Upper Pleistocene Africans who are also ancestral 
TABLE 6. African distribution of nonmetric features shared by Zuttiyeh and the Zhoukoudian crania ${ }^{1}$

\begin{tabular}{|c|c|c|c|c|c|c|}
\hline Features & Bodo & Kabwe & Ndutu & Florisbad & Ngaloba & $\begin{array}{l}\text { Eliye } \\
\text { Springs }\end{array}$ \\
\hline Frontal curvature & $\mathrm{O}$ & 0 & $\ldots$ & - & $\mathrm{O}$ & $\mathrm{X}$ \\
\hline Narrow boss & $\mathrm{O}$ & $\mathrm{O}$ & $\mathrm{O}$ & $\mathrm{O}$ & $\mathrm{O}$ & $\mathrm{O}$ \\
\hline Short temporal notch & $\mathrm{O}$ & $\mathrm{X}$ & - & $\mathrm{O}$ & - & $\mathrm{X}$ \\
\hline $\begin{array}{l}\text { Supratoral sulcus: size \& } \\
\text { morphology }\end{array}$ & $\mathrm{O}$ & 0 & - & $\mathrm{O}$ & $\mathrm{O}$ & $\mathrm{O}$ \\
\hline Glabella depression & $\mathrm{O}$ & $\mathrm{O}$ & - & $\mathrm{O}$ & $\mathrm{x}$ & - \\
\hline Flat nasal root & 0 & $\mathrm{O}$ & 0 & $\mathrm{O}$ & $\mathrm{O}$ & - \\
\hline $\begin{array}{l}\text { Nasal bones flat (transversely or } \\
\text { superiorly) }\end{array}$ & 0 & $\mathrm{O}$ & $\mathrm{O}$ & $\mathrm{X}$ & - & $\mathrm{O}$ \\
\hline Tubercle on zygomatic anterior face & $\mathrm{O}$ & $\mathrm{X}$ & - & $\mathrm{X}$ & - & 0 \\
\hline $\begin{array}{l}\text { Anterolateral orientation of } \\
\text { zygomatic }\end{array}$ & 0 & 0 & - & $X$ & - & $X$ \\
\hline $\begin{array}{l}\text { Unangled superior nasal bones } \\
\text { (vertical orientation) }\end{array}$ & $\mathrm{X}$ & $\mathrm{O}$ & $\mathrm{O}$ & $\mathrm{O}$ & - & $\mathrm{X}$ \\
\hline
\end{tabular}

${ }^{1}$ The character states are defined by the shared features of the Zuttiyeh-Zhoukoudian comparison. For instance, the table indicates that Elive Springs has a frontal that is curved in the sagittal plane in a manner similar to the frontal curvature of Zuttiyeh and the Zhoukoudian sample. $\mathrm{X}=$ present; $\mathrm{O}=$ absent; $-=$ part not preserved.

to the Skhul/Qafzeh hominids according to this theory.

To examine the possibility of an AfricanZuttiyeh relationship, comparisons with the African specimens we regard as having the best chance of dating to a timespan earlier than Zuttiyeh are necessary. These include Kabwe, Bodo, and Ndutu (earlier specimens), and to be conservative also Ngaloba and Florisbad (specimens that are almost certainly too late to be ancestral) and the undated Eliye Springs cranium. We did not include the Jebel Irhoud crania (as urged by two reviewers of this paper) as neither they nor the stratigraphic levels they are said to have been discovered in are directly dated, and in any event their provenience is uncertain. Grün and Stringer (1991:185) report that

the unsystematic collecting procedures used earlier at the site mean that a precise context cannot be provided for Irhoud 1-3.

Moreover, there is little reason to be confident of the ESR dates reported for the cave. The ESR date range for three animal teeth from a single level, 90-190 kyr, throws the accuracy of the ESR date estimate in this cave into serious doubt.

In the comparison with the single female in the earlier African group, Ndutu, none of the features linking Zuttiyeh and Zhoukoudian can be found (Table 6). Expanding the comparisons to include the males, Kabwe and Bodo, still results in only a few similarities--none for all three specimens.

If the later remains from Ngaloba (Laetoli Hominid 18) and Florisbad are also considered potential ancestors, of the 10 morphological comparisons that uniquely link Zuttiyeh and the Zhoukoudian sample, only three link Zuttiyeh with Florisbad, and just one links it with Ngaloba. In fact, Zuttiyeh most closely resembles Eliye Springs (ES 11693) in these features (four are shared). However, only one of these four is also shared with the next most similar specimen, Florisbad. Moreover, Eliye Springs may be much too recent to be ancestral. We find many details of this specimen to resemble other Africans and not Zuttiyeh; for instance, the frontal keel extending to the supraorbitals and interrupting the supratoral sulcus, the flattening of this sulcus at the temporal lines, the length of the frontal from the lateral orbit to the stephanion position on the coronal suture, the keeling of the inter nasal suture, and the depression of the nasal root. We are also concerned that two of the observations suggesting similarity with Zuttiyeh, the vertical orientation of the superior nasals and the flattened infraorbital region, may be affected by crushing.

In all, while gene flow from Africa is a likely source of at least some variation in Levant populations, we find no case for a 
unique or even significant pattern of African ancestry for the western Asians in these data.

\section{EAST ASIAN FEATURES IN LATER LEVANT HOMINIDS}

This leaves the question of whether the features linking Zuttiyeh and the Zhoukoudian specimens can be found in the later Levantine folk, as one would expect if they reflect an ancestral relationship and Zuttiyeh (or her peers) had offspring. While not all comparable parts are preserved, and in spite of the broader frontal in the later female, we find most of the similarities between Zuttiyeh and the Zhoukoudian sample shared by the Tabun woman. This is especially striking in the region surrounding the root of the nose, where Tabun differs dramatically from the European Neandertals (female and male). However, before this is used to make Zuttiyeh into a Neandertal again, we note that in those cases where Zuttiyeh is similar to Tabun, the other Levant Neandertal, Amud, is quite different.

To quantify the comparisons of Zuttiyeh with the other Levant specimens for the east Asian features Zuttiyeh shares with the Zhoukoudian crania, we have prepared Table 5 . This table shows that some of the east Asian features of Zuttiyeh are to be found in both the Levant Neandertal sample and the non-Neandertals (the so-called "moderns"). Cognizant of the uncertainties due to missing data, we nonetheless believe that these similarities are not unique to either of these samples, although both the number and the combination in each specimen is different. Thus, for instance, the similarities surrounding the nasal root region shared with Tabun are all absent in Amud. These particular similarities are, however, shared with Qafzeh 3 and 6. As another example, the specific form of the Zuttiyeh supraorbitals and of the supratoral sulcus are shared with both Tabun and Qafzeh 3.

We do not mean to imply that Tabun shares a unique relationship with Qafzeh 3 and 6. This paper, after all, is not an analysis of the other Levant hominids, and these specimens have many features not preserved in Zuttiyeh that we therefore do not discuss, but would have to discuss to ascertain the pattern of relationship among the Levant specimens. The shared east Asian features in the Tabun and Qafzeh 3 females and the Qafzeh 6 male show that if one accepts the division of the Levant hominids into Neandertal and "modern" samples, both samples show east Asian features and therefore are unlikely to be uniquely African in their origin. Instead, a case based on the east Asian features of Zuttiyeh can be made for significant local continuity in the Levant.

Moreover, the focus on the east Asian features of Zuttiyeh helps explain one more difference between this study and two earlier ones; mainly, the suggested relationship to Skhul 5. McCown and Keith (1939) never specifically addressed the relationship of Zuttiyeh to the Levant sample, but the conclusions we abstracted from the comparisons they made in their text (i.e., Table 1) suggest that the closest phenetic relation of Zuttiyeh is, in fact, with Skhul 5. However, if instead of examining all the possible comparisons, we limit the comparison to only east Asian intraspecies clade features preserved in Zuttiyeh, this specimen is probably in fact least like Skhul 5-a conclusion that may have been reflected in Coon's (1963:574) comments about this Skhul specimen, in which he specifically likened it to Australasians.

In the second study, Hublin also related Zuttiyeh to Skhul 5. In Hublin's (1976) subsequent analysis, there is a contradiction between the conclusions in his text and the systematic comparisons that he provided. His stated conclusion is that Zuttiyeh is much like Skhul 5, while the comparisons he presents (abstracted in our Table 3 ) show it to be least like Skhul 5 . We wonder if this difference between what he thought and what he showed may not reflect the confusion of grade (i.e., "modern") and intraspecies clade (i.e., Asian) features. His analysis surely suggests that the features in which Zuttiyeh is similar to the Zhoukoudian hominids (a relationship he supports) distinguish it from Skhul 5, and therefore what Hublin saw in this specimen may not be too different from our own understanding. 
However, with the collapse of the idea that there are numerous unique Skhul 5-like features shared with Zuttiyeh, we question what evidence exists to suggest that Zuttiyeh is particularly like modern Homo sapiens. Here we differ from Vandermeersch. In fact, some of the specific "modern" features Vandermeersch cites (Table 4) are not modern at all and we suspect he may have confused "modern" with "non-Neandertal." For instance, Figure 1 shows the frontal bone length, which Vandermeersch emphasized, to be both within the Zhoukoudian and the Levant Neandertal ranges, but at the very edge of the Levant non-Neandertal range. This is hardly a unique "modern" feature for Zuttiyeh. Similarly, Vandermeersch regards the frontal curvature index from nasion as "modern," while our data show this index to be totally out of the Levant hominid range, but in the Zhoukoudian range. The orbital marginal tubercle he cites as modern is also found in the Zhoukoudian sample. We find none of his "modern" features to be unique aspects linking Zuttiyeh to a pre-sapiens intraspecies clade.

\section{DISCUSSION AND CONCLUSIONS}

We conclude that Zuttiyeh preserves a number of intraspecies clade features from east Asia, many of which appear in the later populations of the Levant-both the Neandertals and the so-called "modern Homo sapiens" remains. As several have said before us, there is no convincing evidence to suggest that Zuttiyeh is uniquely or more closely related to one of these than it is to the other, whatever the exact level of relationship exists between the later Levant hominid samples. Even given the most liberal possible definition of "anatomically modern Homo sapiens" (cf. Delson, 1988), that includes archaic specimens such as Jebel Irhoud 1, we do not believe it is possible to regard Zuttiyeh as "anatomically modern Homo sapiens," unless the entire later Levant sample is also characterized this way.

Clearly east Asian features are in the Levant Neandertal sample. But the two most complete Levant Neandertal adult crania do not have the same east Asian features; Tabun retains many more than does Amud (because of an earlier date?). Moreover, numerous east Asian characteristics are also found in Skhul and Qafzeh specimens, again in some more than in others. In many cases these are the features characterized as "modern" in earlier publications, but we have shown them to be east Asian rather than "modern," thereby substituting an intraspecies clade explanation for a grade one. Zuttiyeh shows the highest number of Zhoukoudian-like features of all the Levant specimens, perhaps because it is the earliest; its range of estimated dates, after all, could bring it quite close to Zhoukoudian in terms of its age. Our hypothesis of a Zhoukoudian ancestry best explains the origin of the non-Neandertal features in the Levant hominids. The source is geographic, and east Asian rather than African.

These data do not obviously demonstrate that the Levant Neandertals are intrusive, refugees from the severe conditions of the last European glaciation as Vandermeersch (1981), Bar-Yosef (1988), and others have suggested (see also Trinkaus, 1991). In fact it is clear to us that if migration into the region was the case, differences with the cold-adapted Neandertals of Europe suggest that at least some of the Levant Neandertals are not the refugees themselves, but rather are their descendants. These descendants, in this interpretation, show evidence of mixture with the local populations because many of the (local) east Asian features appear in the Levant Neandertals.

The (local) east Asian features we have identified also appear, to a greater or lesser extent, in the non-Neandertal Levantine sample, and we believe there is clear evidence in these data to support the following two contentions. (1) The Levant Neandertals are not more than racially distinct from the non-Neandertal populations of the region. The evidence of interbreeding between any intrusive Neandertal population and the descendants of Zuttiyeh (i.e., hybridization) strongly suggests they cannot be different species. (2) If we can assume that any of these Levant populations (Neandertal, nonNeandertal, or both) are ancestral to living people, the significant elements of earlier east Asian ancestry in the late Pleistocene populations of the Levant demonstrates 
that no known African population can be the unique ancestor of all modern populations.

In sum, Zuttiyeh plays an important role in understanding the evolutionary pattern in the Middle and Upper Pleistocene of the Levant. It cannot be shown to uniquely underlie either a local Neandertal or a local "anatomically modern" intraspecies clade in the region. It seems to link both of these later Levant samples with the earlier remains from east Asia, thereby invalidating any contention of a unique $200 \mathrm{kyr}$ or younger African ancestry for modern populations. It would appear that features regarded as "modern" were actually "non-Neandertal," in many cases because they were east Asian. It is this potential for confusing a grade with an intraspecies clade explanation that in our opinion underlies the lack of earlier agreement about the relations of Zuttiyeh-a lack of agreement at least twice characterizing the difference between the analysis and conclusions of the same paper. But for this confusion, many who have reported on the specimen would seem to concur that it presents a reasonable and not unexpected morphology for an early Levant hominid.

We add to this understanding a link with earlier east Asian morphology, especially as expressed at Zhoukoudian, where the more complete specimens in the region are found. Perhaps the Late Pleistocene extension of the European (i.e., Neandertal) morphology into the Crimea and even further into central Asia, such as represented at Zaskalnaya and Teshik Tash, was a temporally limited and misleading (at least for today's paleoanthropologists) interruption of a different, more normal Pleistocene distribution of populations. The east Asian features in Zuttiyeh, combined with what we regard as the east Asian relations of the (probably) earlier Narmada vault from India, suggest a broader Pan-Asian distribution of regional features than is normally recognized. We think that the links between Zuttiyeh and the east Asian hominids are not expected, because there are probably more general links between the Levant hominids and many populations just to the east. It is this set of east Asian features that provides the genesis of at least some of the non-Neander- tal characteristics in the Levant populations, but non-Neandertal is not necessarily modern, and unless one believes that all modern human populations have a unique recent origin in Asia, it is clear that region as well as evolutionary stage could profitably be included as a valid source of Pleistocene human variation.

\section{ADDENDUM}

Yoel Rak has been re-examining the deposits at the base of the Zuttiyeh cave, and several years ago wrote us that he had made an exciting new discovery. When he sent a cast of the Kebara pelvis, included in it was a box labeled "Newly Discovered at the Base of the Zuttiyeh Cave." In the box was a fortune cookie.

\section{ACKNOWLEDGMENTS}

This paper was first prepared for the International Symposium on Palaeoanthropology in Commemoration of the 60th Anniversary of the Discovery of the First Skull of Peking Man, held in Beijing (October 19 through 24,1989 ). A short version was presented at the 1990 AAPA meetings. T. Simmons, A.B. Falsetti, and F.H. Smith graciously made available their unpublished material on Zuttiyeh. O. Bar-Yosef, E. Trinkaus, and G. Pope and B.A. Wood provided a number of helpful comments and suggestions. We also thank the following individuals who made the original specimens available for our study: J. Zias of the Rockefeller Institute, C.B. Stringer of the Natural History Museum, Y. Rak of the University of Tel Aviv, W.W. Howells of the Peabody Museum, Harvard University, B. Vandermeersch of the Universite de Bordeaux, and J.-L. Heim of the Institute de Paléontologie Humaine, Paris.

\section{LITERATURE CITED}

Bar-Yosef O (1988) The date of South-West Asian Neandertals. In M Otte (ed.): L'Homme de Neandertal. Vol. 3: L'Anatomie. Liège: Etudes et Recherches Archéologiques de l'Université de Liège. 30:31-38.

Bar-YosefO (1989) Geochronology of the Levantine Middle Paleolithic. In P Mellars and C Stringer (eds.): The Human Revolution: Behavioral and Biological Perspectives on the Origins of Modern Humans. Edinburgh: Edinburgh University Press, pp. 589-610. 
Bar-Yosef O (1992) The role of Western Asia in modern human origins. Philos. Trans. R. Soc. Lond. [Biol.] $337: 193-200$.

Coon C (1963) The Origin of Races. New York: Knopf.

Copeland L, and Hours F (1983) Le Yabroudien d'ElKowm (Syrie) et sa place dans le Paléolithiques du Levant. Paléorient 9:21-38.

Delson E (1988) One source not many. Nature 318:107108.

Dobzhansky T (1944) One species and races of living and fossil man. Am. J. Phys. Anthropol. 2(3):251-265.

Etler, DA (1990) A case study of the "erectus"- "sapiens" transition in Asia: Hominid remains from Hexian and Chaoxian Counties, Anhui Provence, China. Kroeber Anthropological Society Papers 71-72:1-19.

Garrod D (1962) The Middle Paleolithic of the Near East and the problem of Carmel men. J. R. Anthropol. Inst. 92:232-259.

Gisis I, and Bar-Yosef O (1974) New excavation in Zuttiyeh Cave, Wadi Amud, Israel. Paléorient 2:175-180.

Gould SJ (1989) Grimm's greatest tale. Nat. Hist. 2/89:20-28.

Grün R, and Stringer CB (1991) Electron spin resonance dating and the evolution of modern humans. Archaeometry 33(2):153-199.

Habgood, PJ (1992) The origin of anatomically modern humans in East Asia. In G Bräuer and FH Smith (eds.): Continuity or Replacement? Controversies in Homo sapiens Evolution. Rotterdam: Balkema, pp. 273-288.

Holt BM, and Waddle DM (1991) The affinities of the Zuttiyeh frontal reconsidered (abstract). Am. J. Phys. Anthropol. [Suppl.] 12:95.

Howell FC (1953) Upper Pleistocene men of the Southwest Asian Mousterian. In GHR von Koenigswald (ed.): Hundert Jahre Neanderthaler. Utrecht: Kemink en zoon, pp. 185-198.

Hrdlička A (1930) The skeletal remains of early man. In Smithsonian Institution Annual Report for 1928. pp. 593-623.

Hublin $J-J$ (1976) Lhomme de Galliée, Mémoire de D.E.A de Paléontologie. Paris: Université de Paris VI.

Hublin J-J (1983) Les origins de l'hommes de type moderne en Europe. Science 62:62-71.

Hublin J-J (1987) Qui fut l'Ancestre de l'Homo sapiens? Science 113:26-35.

Huxley JS (1958) Evolutionary processes and taxonomy, with special reference to grades. Uppsala Univ. Arssks. 1958:21-38.

Jelinek A (1981) The Middle Paleolithic in the Southern Levant from the perspective of the Tabun Cave. In J Cauvin and P Sanlaville (eds.): Prehistoire du Levant. Paris: Centre National de la Recherche Scientifique, pp. 265-280.

Keith A (1927) A report on the Galilee skull. In TurvillePétre F (ed.): Researches in Prehistoric Galilee, 19251926. London: Council of the British School of Archaeology in Jerusalem, pp. 593-623.

Keith A (1931) New Discoveries Relating to the Antiquity of Man. London: Williams and Norgate.

McCown TD, and Keith A (1939) The Stone Age of
Mount Carmel: The Human Remains from the Levallois-Mousterian. Vol. II. Oxford: The Clarendon Press. Rak Y (1986) The Neanderthal: a new look at an old face. J. Hum. Evol. 15(3):151-164.

Rak Y (1990) On the difference between two pelvises of Mousterian context From the Qafzeh and Kebara Caves, Israel. Am. J. Phys. Anthropol. 18:323-332.

Schwarcz H, Goldberg P, and Blackwell B (1980) Uranium series dating of archaeological sites in Israel. J. Earth Sci. 29:157-165.

Simmons T, Falsetti AB, and Smith FH (1991) Frontal bone morphometrics of Southwest Asian Pleistocene hominids. J. Hum. Evol. 20:249-269.

Smith FH (1985) Continuity and change in the origin of modern Homo sapiens. Z. Morphol. Anthropol. $75: 197-222$.

Stringer C (1985) Middle Pleistocene hominid variability and the origin of Late Pleistocene humans. In E Delson (ed.): Ancestors: The Hard Evidence. New York: Alan R. Liss, Inc. pp. 289-295.

Stringer C (1990) The emergence of modern humans. Sci. Am. 263(6):98-104.

Stringer C, and Andrews P (1988) Modern human origins. Science 241:773-774.

Stringer C, Hublin J-J, and Vandermeersch B (1984) The origin of anatomically modern humans in western Europe. In FH Smith and F Spencer (eds.): The Origins of Modern Humans: A World Survey of the Fossil Evidence. New York: Alan R. Liss, Inc., pp. 51-135.

Suzuki H, and Takai F (eds) (1970) The Amud Man and His Cave Site. Tokyo: University of Tokyo Press.

Trinkaus E (1983) The Shanidar Neandertals. New York: Academic Press.

Trinkaus E (1984) Western Asia. In FH Smith and F Spencer (eds.): The Origins of Modern Humans: A World Survey of the Fossil Evidence. New York: Alan R. Liss, Inc., pp. 251-293.

Trinkaus E (1989) Issues concerning human emergence in the later Pleistocene. In Trinkaus $\mathbf{E}$ (ed.): The Emergence of Modern Humans: Biological Adaptations in the Later Pleistocene. Cambridge: Cambridge University Press, pp. 1-17.

Trinkaus E (1991) Les Hommes Fossile de la Grotte de Shanidar, Irak: Evolution et Continuité parmi les Hommes Archaiques Tardifs du Proche Orient. L'Anthropologie (in press).

Turville-Pêtre F (ed.) (1927) Researches in Prehistoric Galilee, 1925-26. London: Council of the British School of Archaeology in Jerusalem.

Vandermeersch B (1981) Les premiers Homo sapiens au Proche Orient. In D Ferembach (ed.): Le Processus de l'hominisation. Paris: Centre National de la Recherche Scientifique, pp. 97-100.

Vandermeersch B (1989) The evolution modern humans: Recent evidence from Southwest Asia. In P Mellars and C Stringer (eds.): The Human Revolution. Edinburgh: Edinburgh University Press, pp. 155-164.

Weidenreich F (1943) The skull of Sinanthropus Pekinensis: a comparative study of a primitive hominid skull. In Paleontologia Sinica (n.s.D) 10 (Whole Series 127). Beijing: Geological Survey of China. 
Wolpoff MH (1980) Paleoanthropology. New York: Knopf. Wolpoff MH, Smith FH, Malez M, Radovcić J, and Rukavina D (1981) Upper Pleistocene human remains from Vindija Cave, Croatia, Yugoslavia. Am. J. Phys. Anthropol. 54:499-545.

Wolpoff MH, Wu X, and Thorne AG (1984) Modern homo sapiens origins: A general theory of hominid evolution involving the fossil evidence from East Asia. In FH Smith and F Spencer (eds): The Origins of Modern Humans: A World Survey of the Fossil Evidence. New York: Liss, pp. 411-483.
Woo J (1966) The skull of Lantian man. Curr. Anthropol. 7:83-86.

Wu $\mathrm{R}$, and Dong X (1982) Homo erectus in China. In $\mathrm{R}$ Wu and JW Olsen (eds.): Paleoanthropology and Paleolithic Archeology in the People's Republic of China. New York: Academic Press, pp. 79-89.

Wu X, and Wu M (1985) Early Homo sapiens in China In R Wu and JW Olsen (eds.): Paleoanthropology and Paleolithic Archaeology in the People's Republic of China. New York: Academic Press, pp. 91-106. 